\title{
Retrieval of CO from SCIAMACHY onboard ENVISAT: detection of strongly polluted areas and seasonal patterns in global $\mathrm{CO}$ abundances
}

\author{
C. Frankenberg, U. Platt, and T. Wagner \\ Institute of Environmental Physics, Heidelberg, Germany \\ Received: 2 November 2004 - Published in Atmos. Chem. Phys. Discuss.: 20 December 2004 \\ Revised: 29 March 2005 - Accepted: 9 May 2005 - Published: 27 June 2005
}

\begin{abstract}
SCIAMACHY onboard the European environmental research satellite ENVISAT is an UV/visible/nearinfrared spectrometer providing 3 near infrared channels covering wavelengths from $1-1.75 \mu \mathrm{m}, 1.94-2.04 \mu \mathrm{m}$ and $2.26-$ $2.38 \mu \mathrm{m}$ with moderate spectral resolution $(0.22-1.5 \mathrm{~nm})$. From their structured absorption in these spectral regions, we can quantitatively determine the total column densities of the greenhouse gases $\mathrm{CO}_{2}, \mathrm{CH}_{4}, \mathrm{~N}_{2} \mathrm{O}$ and $\mathrm{H}_{2} \mathrm{O}$ as well as of CO. A modified DOAS algorithm based on optimal estimation (IMAP-DOAS) has been developed at the University of Heidelberg to account for the peculiarities of these absorbers. $\mathrm{CO}$ is a relatively weak absorber whose spectral signature is overlapped by strong $\mathrm{CH}_{4}$ and $\mathrm{H}_{2} \mathrm{O}$ absorptions. Hence, retrieval of CO from SCIAMACHY spectra (within 2.26$2.38 \mu \mathrm{m}$ ) is a challenging task. Therefore, the calibration of the raw spectra with respect to dark current issues and nonlinearity were analysed in detail and substantially improved to enable reasonable retrieval of $\mathrm{CO}$. This paper focusses on first results of the $\mathrm{CO}$ retrieval where various sources like biomass burning events and their seasonal variability can be clearly identified.
\end{abstract}

\section{Introduction}

$\mathrm{CO}$ is one of the most important pollutants in the troposphere and although $\mathrm{CO}$ itself is not a greenhouse gas, it has an indirect effect on climate as sink for the $\mathrm{OH}$ radical, thus leading to longer lifetime of direct greenhouse gases such as $\mathrm{CH}_{4}$ (IPCC, 2001). The main sources are presumed to be biomass burning, oxidation of hydrocarbons and methane as well as fossil fuel use (Holloway et al., 2000). It has already been measured by spaceborne instruments, namely by MAPS (Measurement of Air Pollution from Satellite) onboard space

Correspondence to: C. Frankenberg

(cfranken@iup.uni-heidelberg.de) shuttles in 1981, 1984, and 1994 (Reichle Jr. et al., 1999) and by the Interferometric Monitor for Greenhouse gases (IMG) onboard ADEOS from August 1996 to June 1997 (Kobayashi et al., 1999). MOPITT onboard EOS-TERRA since 1999 (Deeter et al., 2003) is still in orbit measuring global CO abundances using the gas correlation technique in the thermal infrared.

SCIAMACHY is the first instrument that allows retrieval of $\mathrm{CO}$ by measuring absorption in the near infrared, i.e. observing reflected and scattered sunlight instead of thermal emission (Buchwitz et al., 2004). Thus, the integrated concentration of $\mathrm{CO}$ along the light path (the slant column density, SCD) can be inferred from the ratio of nadir radiance and solar irradiance spectra using the DOAS method (Platt, 1994). The near infrared spectral region has the advantage that there is little scattering within the atmosphere, thus most of the measured photons are directly reflected from the earth's surface (for cloud-free scenes and sufficiently high surface albedo). Thus, $\mathrm{CO}$ measurements by SCIAMACHY are, in contrast to thermal emission sounders, highly sensitive to lower layers of the troposphere where the sources are located and the bulk of the CO SCD is usually found. This is of special importance for the detection of enhanced $\mathrm{CO}$ abundances in the boundary layer, thus particularly of interest for human health issues.

\section{The SCIAMACHY instrument and data analysis}

SCIAMACHY onboard the European Space Agencies environmental research satellite ENVISAT consists of 8 grating spectrometers measuring in the ultraviolet, visible and near infrared wavelength region $(240 \mathrm{~nm}-2380 \mathrm{~nm})$ (Bovensmann et al., 1999). The satellite operates in a near polar, sun-synchronous orbit at an altitude of $800 \mathrm{~km}$ and a local equator crossing time at approximately 10:00 am. In each orbit, a swath width of $960 \mathrm{~km}$ across track with a maximum

(C) 2005 Author(s). This work is licensed under a Creative Commons License. 


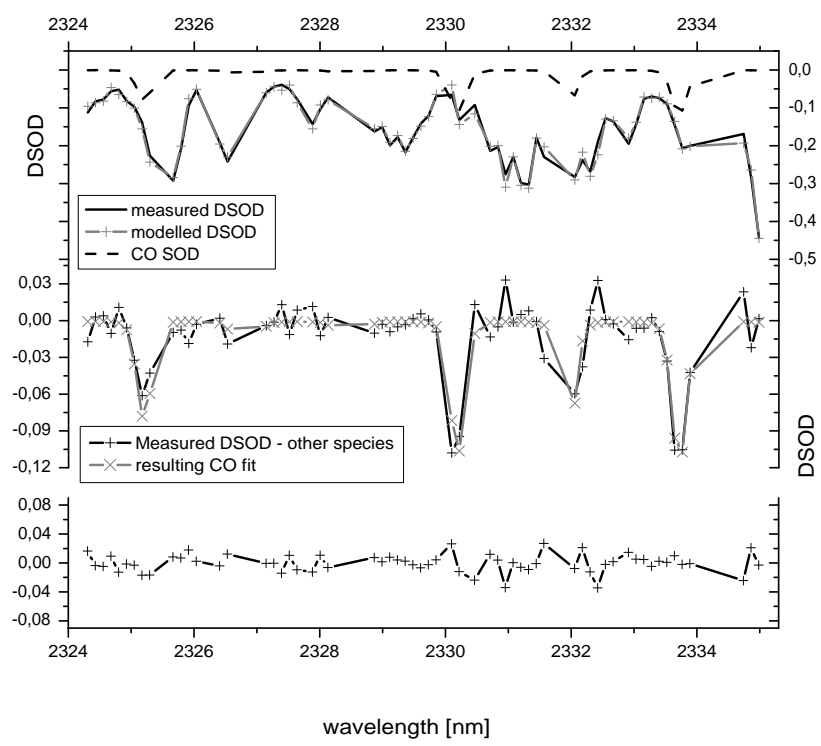

Fig. 1. Example of a $\mathrm{CO}$ fit with relatively strong $\mathrm{CO}$ absorptions $\left(V C D \approx 8 \times 10^{18} \mathrm{molec} / \mathrm{cm}^{2}\right)$. The upper panel shows the differential slant optical density (DSOD) of all absorbers $\left(\mathrm{CH}_{4}, \mathrm{H}_{2} \mathrm{O}\right.$ and $\mathrm{CO}$ ) as well as that of $\mathrm{CO}$ separated (dashed line). The centre panel shows the measured slant optical density with the slant optical density of $\mathrm{CH}_{4}$ and $\mathrm{H}_{2} \mathrm{O}$ subtracted in order to depict only the absorption structures of $\mathrm{CO}$. The lower panel shows the residual of the fit (please note the different scale).

pixel resolution of $26 \mathrm{~km} \times 15 \mathrm{~km}$ is covered, thus being a substantial improvement to the large footprint of the predecessor instrument GOME onboard ERS-2. Global coverage is achieved every six days. For the $\mathrm{CO}$ retrieval, the typical ground pixel size is $30 \mathrm{~km}$ (along track) times $120 \mathrm{~km}$ (across track).

SCIAMACHY is designed to measure sunlight that is either transmitted, reflected or scattered by the earth's atmosphere or surface. For this purpose it has 3 viewing geometries, Nadir, Limb and Occultation. This work focusses only on Nadir spectra because they yield detailed information on the tropospheric $\mathrm{CO}$ abundance. We discuss instrument calibration issues, the development of a new algorithm and results of the CO retrieval.

\subsection{Retrieval algorithm}

In contrast to the UV/Vis spectral region, the near infrared exhibit peculiarities that render classical DOAS algorithms for CO retrieval unsuitable: First, there is a strong sensitivity to temperature and pressure of the strong and narrow absorption lines that are not fully resolved by the spectral resolution of the instrument, thus making the retrieval nonlinear. Second, the weak CO absorptions are overlapped by strong methane and water vapour lines whose interferences are stronger than the $\mathrm{CO}$ absorption itself. Buchwitz et al. (2000) were the first to focus on the near infrared and intro-

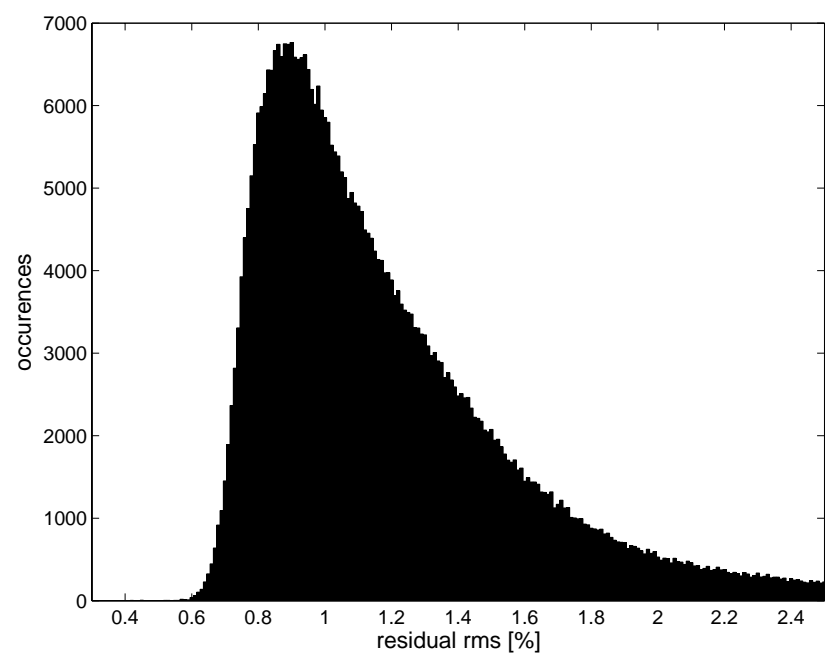

Fig. 2. Histogram of the RMS of the fit residual for the CO retrieval in channel 8 during July 2004.

duced the concept of weighting function modified (WFM)DOAS. To account for the general nonlinearity of the problem and to avoid interferences between strong absorbers, we developed a new iterative maximum a posteriori DOAS (IMAP-DOAS) (Frankenberg et al., 2005) at the University of Heidelberg. The algorithm is based on optimal estimation theory introduced to the remote sensing community by Rodgers (1976). This method directly iterates the vertical column densities of the absorbers of interest until the expected spectral signature of the total optical density fits the measurement. It accounts for nonlinearities due to spectrally non-resolved strong absorptions and considers sensitivity to pressure and temperature changes in the atmospheric profile. This algorithm minimises systematic biases that would occur in classical DOAS algorithms. A detailed description of the algorithm can be found in Frankenberg et al. (2005). Other research groups, e.g. Schrijver (2004), also developed modified algorithms for the near infrared spectral region and some preliminary results are shown by Buchwitz et al. (2004) and Gloudemans et al. (2004).

The CO retrieval turned out not only to be a challenging task from a spectroscopic point of view, but also due to instrumental issues: An ice layer on the near infrared detectors affects dark current and the instrumental function. These are important issues and have to be analysed and corrected in detail.

\subsection{Spectral calibration, dark current and nonlinearity}

The near infrared channels exhibit a substantially higher dark current than the UV/Vis channels of SCIAMACHY. In addition to this complication, the leakage current (the time dependent part of the dark current) and the fixed pattern noise are not a smooth function but show strong variations over the 
entire detector array. Due to the variable ice deposition on the detectors, the dark current and even the slit function show time dependent behaviour (Kleipool, 2004). Thus, a simple correction is not possible and the expected operational correction algorithms (Slijkhuis, 2001) have not yet solved the problem.

Due to these crucial problems, a reasonable retrieval of $\mathrm{CO}$ is not possible without application of sophisticated calibration methods. A first correction scheme has been implemented in the current IMAP-DOAS algorithm using daily readouts of the dark current to correct the raw spectra with the respective pixel exposure times (as initially proposed by the instrument PI, J. Burrows, see technote by Kleipool (2003a)). Furthermore, the standard deviations of the daily dark current readouts are used in the algorithm to generate a daily dead/bad pixel mask and for the weighting of the available pixels in the weighted least squares fit according to their dark current stability. Since the dark current can also vary over the orbit (Kleipool, 2004), a first order dark current offset correction has been implemented as the fit factor in our algorithm. In addition to these complications, the detector pixels exhibit a nonlinearity (Kleipool, 2003b) that has not yet been considered in the operational calibration tools (Slijkhuis, 2001). The proposed correction by Kleipool (2003b), which treats even and odd detector pixels separately, has been implemented in our correction scheme. These modifications substantially improved the $\mathrm{CO}$ retrieval in channel 8 of SCIAMACHY.

\subsection{Spectral fitting}

For the retrieval of CO, a fit window between 2324 and 2335 $\mathrm{nm}$ was chosen. Due to the decline of instrument sensitivity towards larger wavelengths, this has been found to be an optimal fitting window with respect to signal to noise ratio. $\mathrm{CO}$ is a relatively weak absorber whose absorption lines are superposed by strong absorptions by $\mathrm{CH}_{4}$ and $\mathrm{H}_{2} \mathrm{O}$.

The root mean square (RMS) of the (not-weighted) residual of the fit in this wavelength range is typically about $0.9 \%$ (see Fig. 2). Considering this residual only as noise in the spectra, an upper limit of the statistical errors (standard deviation) in the CO column is about $3 \times 10^{17} \mathrm{molec} / \mathrm{cm}^{2}$.

All outliers in the retrievals are masked by using only fits where the root mean square of the residual is below $1.7 \%$ and the statistical error of the $\mathrm{CO}$ vertical column density is below $30 \%$. This subset of appropriate retrievals can then be used for the analysis of the global distribution and variations of $\mathrm{CO}$ vertical column densities.

\subsection{Aims}

The aim of the CO retrieval is to detect global patterns and variations in the total column abundances of $\mathrm{CO}$. Although the highest mixing ratios are expected in the boundary layer, which is sometimes shielded from satellite observations by clouds, a substantial amount of CO can also be present above the clouds. Thus, all observations have been taken into account for the analysis and cloud-covered pixels have not been masked out.

However, in order to account for clouds and other processes that can artificially diminish the retrieved total column, global pictures of $\mathrm{CO}$ for a certain time period are depicted as described in the following. Pixels (meeting the criteria described in Sect. 2.3) with higher VCD's are displayed above pixels with lower VCD's. This procedure unveils the patterns of maximum $\mathrm{CO}$ abundances. Since clouds usually diminish the retrieved columns, this method also hides measurements that might be artificially reduced. Nevertheless, in some areas no cloud free conditions might have occurred within the given time periods, biasing the observed maximum values. Future work will take more sophisticated cloud algorithms into account, using information on cloud top-height and cloud cover.

\section{Results}

Monthly maps created as described above are a useful method to show the general patterns of $\mathrm{CO}$ abundance and their seasonal variations. Figure 3 depicts the maximum $\mathrm{CO}$ $\mathrm{VCD}$ for a whole year divided into bimonthly periods ranging from September 2003 to August 2004. Since most CO sources are located in the northern hemisphere, a clear northsouth gradient can be identified. This finding substantiates that even low column abundances can be measured by SCIAMACHY.

Further, large-scale $\mathrm{CO}$ enhancements with seasonal variations can also be clearly identified in Africa, South America and Southeast Asia. In March and April, we retrieved vertical columns in Thailand and India with values of up to $6.5 \times 10^{18} \mathrm{molec} / \mathrm{cm}^{2}$. Biomass burning is presumed to mostly contribute to these seasonal patterns of strong enhancements in $\mathrm{CO}$. The seasonal variations of the global distribution of biomass burning events can be well observed by MODIS (Moderate Resolution Imaging Spectroradiometer) aboard Terra. Figure 4 shows fire counts made by MODIS from September 2003 through February 2004. The areas with high fire frequencies correlate well with high abundances of $\mathrm{CO}$, substantiating the assumption that the $\mathrm{CO}$ enhancements stem from biomass burning. Also striking are the enhanced CO concentrations in South-America in September/October 2003, coinciding with the typical period of fires in this region. In this context it has to be noted that, particularly in the tropics, oxidation of hydrocarbons can also be a substantial source of CO.

However, there are also patterns of $\mathrm{CO}$ enhancements that do not exhibit strong seasonality: The region around Bejing in China shows high $\mathrm{CO}$ abundances over the whole time period and can be associated with high industrial activities. 


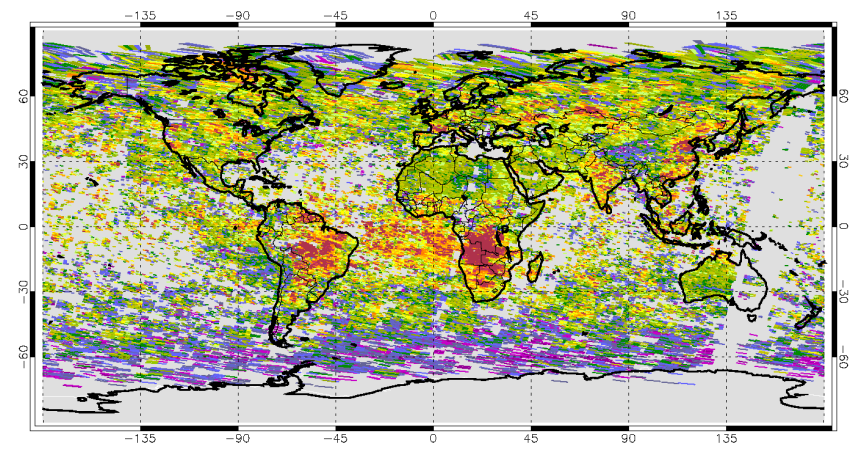

(a) $09-10 / 2003$

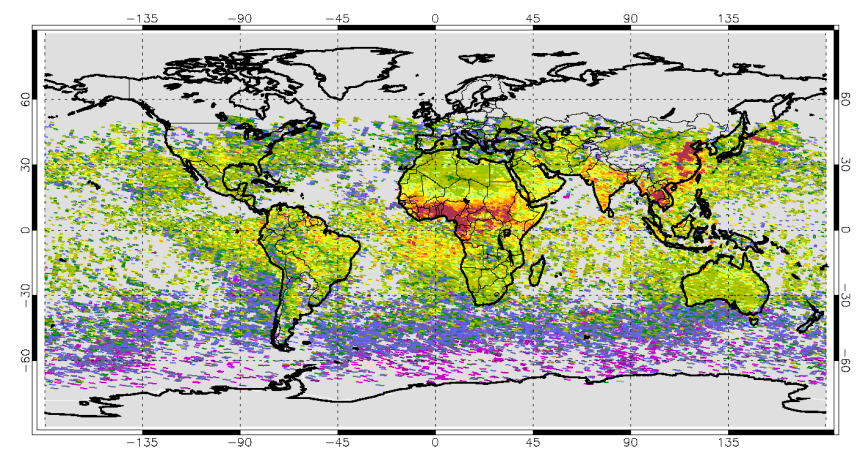

(c) $01-02 / 2004$

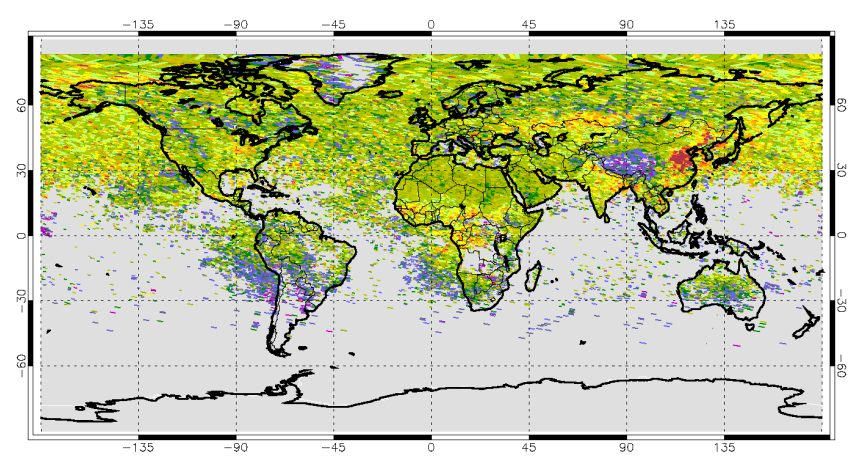

(e) $05-06 / 2003$

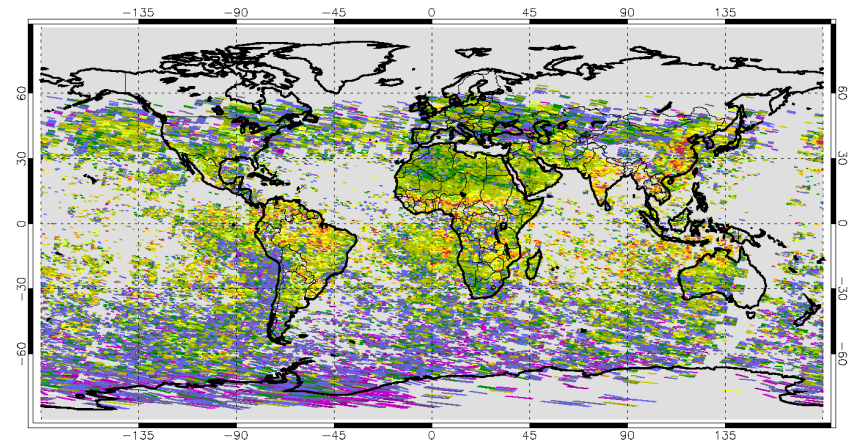

(b) $11-12 / 2003$

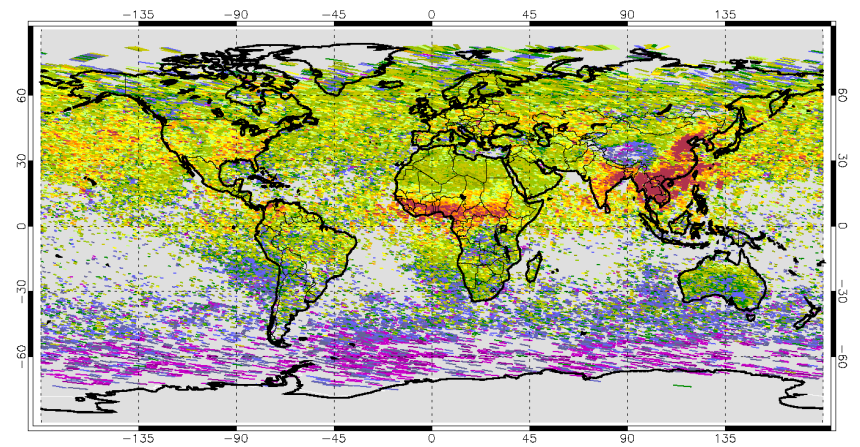

(d) $03-04 / 2004$

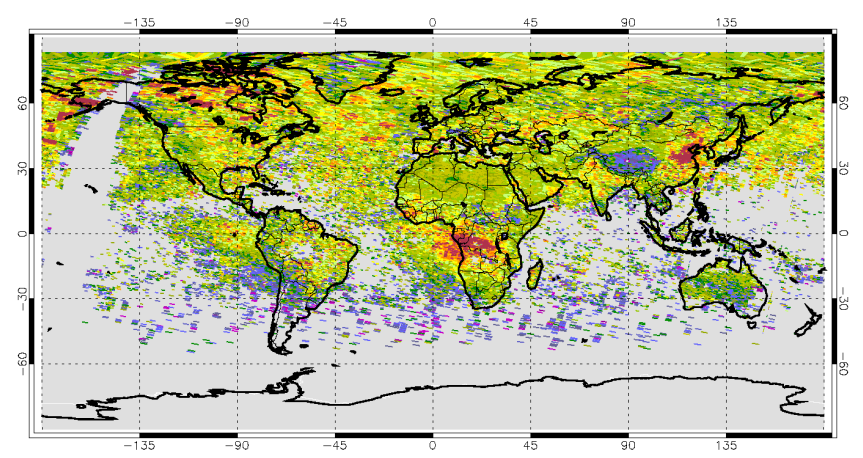

(f) $07-08 / 2004$

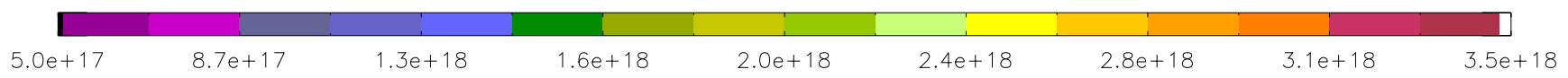

Fig. 3. Maximum observed CO vertical column density [molec/ $\left./ \mathrm{cm}^{2}\right]$ in six two-month periods from September 2003 to August 2004. $1 \times 10^{18} \mathrm{molec} / \mathrm{cm}^{2}$ correspond roughly to an column-averaged CO mixing ratio of $50 \mathrm{ppbv}$. Enhancements due to seasonal variations of biomass burning (e.g. in Africa), constant anthropogenic sources (e.g. China) or sporadic fires (e.g. Alaska in July/August 2004) can be observed (see text). Although the CO columns are not averaged over the given time periods, the patterns of enhancements appear rather smooth, proving the good fit quality and the absence of outliers. Over certain areas (gray), no suitable measurements are available due to very low surface albedo (e.g. over the ocean) or too high solar zenith angles. 


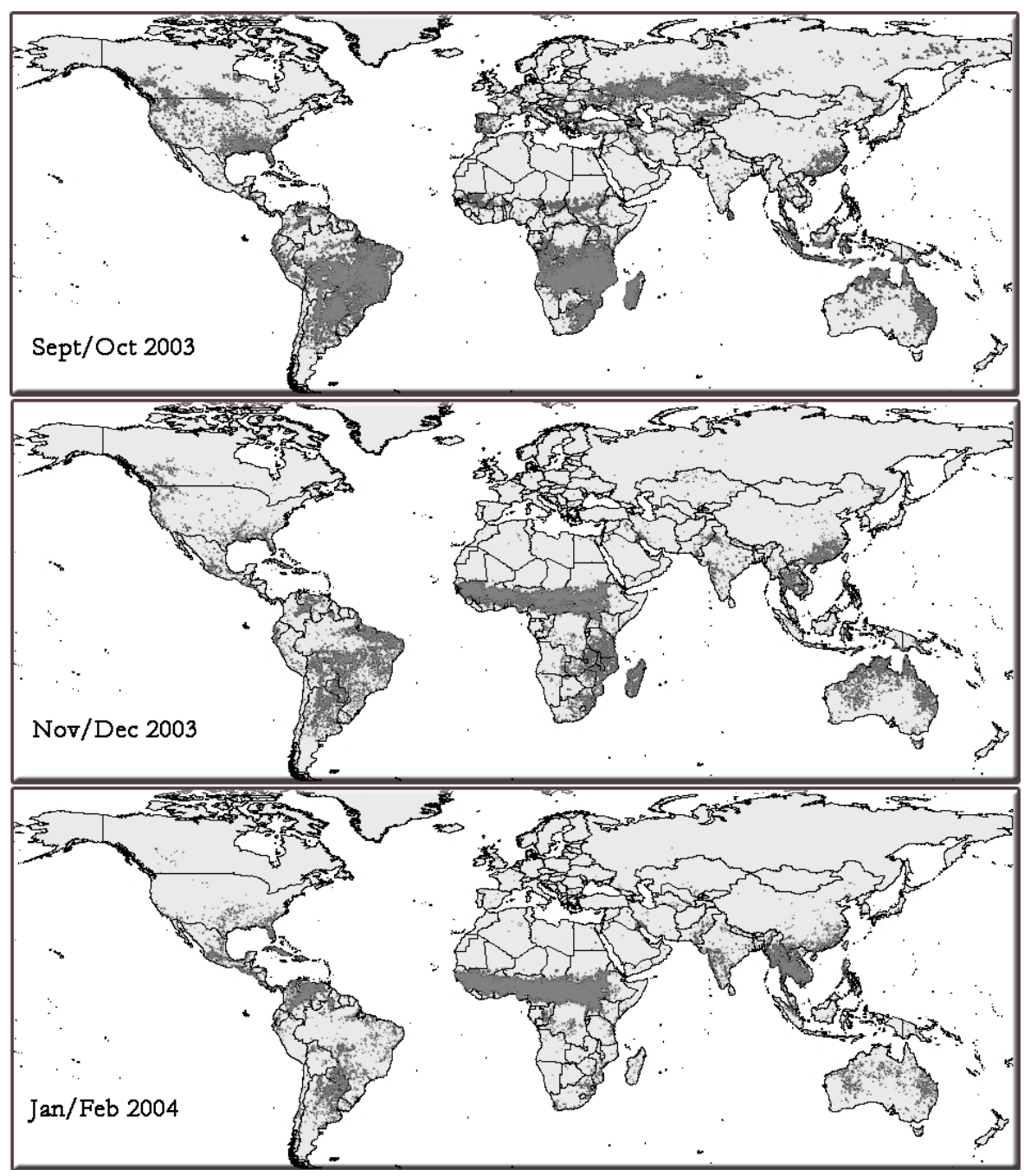

Fig. 4. Bimonthly fire distributions from September 2003 through February 2004. Displayed are fire counts measured by MODIS aboard Terra. At the time of publication, no newer data than February 2004 were available.

These values also peaked at about $7 \times 10^{18} \mathrm{molec} / \mathrm{cm}^{2}$ in March/April 2004.

In addition to these seasonal and constant sources, there are $\mathrm{CO}$ enhancements due to occasionally occurring fires, such as in Alaska and northern Canada (July/August 2004, forest fires) or Kazakhstan in September and October 2003.

\section{Conclusions}

For the retrieval of CO from SCIAMACHY near infrared spectra, we implemented several important spectral calibration procedures and applied our newly developed IMAPDOAS algorithm (Frankenberg et al., 2005) to account for the peculiarities of the near infrared and the $\mathrm{CO}$ retrieval in particular. We have demonstrated that SCIAMACHY can perform global measurements of the CO total column density with high sensitivity even to the boundary layer. Al- though the calibration of the spectra and the slit function posed some serious problems the solutions to which have yet to be perfected, first results are very encouraging and demonstrate that SCIAMACHY is able to detect $\mathrm{CO}$ globally with sufficient accuracy. We observed seasonal variations of biomass burning events as well as enhancements due to anthropogenic activities such as in China. Furthermore, we detected sporadic biomass burning events in various regions on earth. Thus, our observations provide important information on tropospheric chemistry issues on a global scale.

More efforts in the calibration of the spectra and a diminishing ice deposition on the detectors will further improve fit quality and retrieval results. Using longer time periods, will enable us to analyse the correlation of industrial activities and biomass burning with $\mathrm{CO}$ in more detail. 
Acknowledgements. The authors wish to thank all people involved in the SCIAMACHY and ENVISAT mission, especially ESA/ESTEC, DLR, SRON, KNMI and of course the IUP Bremen team, especially J. P. Burrows without whom SCIAMACHY would not have been possible. We are also very grateful to A. Piters and J. van de Vegte from KNMI for their immense help in handling SCIAMACHY data.

Edited by: J. Fishman

\section{References}

Bovensmann, H., Burrows, J. P., Buchwitz, M., Frerik, J., Noël, S., Rozanov, V. V., Chance, K. V., and Goede, A.: SCIAMACHY mission objectives and measurement modes, J. Atmos. Sci., 56, 127-150, 1999.

Buchwitz, M., Rozanov, V., and Burrows, J.: A near-infrared optimized DOAS method for the fast global retrieval of atmospheric $\mathrm{CH}_{4}, \mathrm{CO}, \mathrm{CO}_{2}, \mathrm{H}_{2} \mathrm{O}$, and $\mathrm{N}_{2} \mathrm{O}$ total column amounts from SCIAMACHY Envisat-1 nadir radiances, J. Geophys. Res., 105, 15 231-15 245, 2000.

Buchwitz, M., Beek, R., Bramstedt, K., No“1, S., Bovensmann, H., and Burrows, J.: Global carbon monoxide as retrieved from SCIAMACHY by WFM-DOAS, Atmos. Chem. Phys., 4, 19451960, 2004,

\section{SRef-ID: 1680-7324/acp/2004-4-1945.}

Deeter, M. N., Emmons, L. K., Francis, G. L., Edwards, D. P., Gille, J. C., Warner, J. X., Khattatov, B., Ziskin, D., Lamarque, J.-F., Ho, S.-P., Yuding, V., Attie, J.-L., Packman, D., Chen, J., Mao, D., and Drummond, J. R.: Operational carbon monoxide retrieval algorithm and selected results for the MOPITT instrument, J. Geophys. Res., 108, 4399-4409, 2003.

Frankenberg, C., Platt, U., and Wagner, T.: Iterative maximum a posteriori (IMAP)-DOAS for retrieval of strongly absorbing trace gases: Model studies for $\mathrm{CH}_{4}$ and $\mathrm{CO}_{2}$ retrieval from near infrared spectra of SCIAMACHY onboard ENVISAT, Atmos. Chem. Phys., 5, 9-22, 2005,

SRef-ID: 1680-7324/acp/2005-5-9.

Gloudemans, A., Schrijver, H., Straume, A., Aben, I., Maurellis, A., Buchwitz, M., de Beek, R., Frankenberg, C., and Wagner, T.: $\mathrm{CH}_{4}$ and $\mathrm{CO}$ total columns from SCIAMACHY: comparisons with TM3 and MOPITT, in: Remote Sensing of Clouds and the Atmosphere VIII, vol. 5235 of Proceedings ACVE2, 3-7 May, Frascati, Italy, 2004.
Holloway, T., II, H. L., and Kasibhatla, P.: Global distribution of carbon monoxide, J. Geophys. Res., 105, 12 123-12 147, 2000.

IPCC: Climate Change 2001: The Scientific Basis, Summary for Policy Makers, IPCC (Intergovernmental Panel on Climate Change) Third Assessment Report, (available at: http://www. ipcc.ch/), 2001.

Kleipool, Q.: Algorithm Specification for Dark Signal Determination, Tech. rep. SRON-SCIA-PhE-RP-009, SRON, 2003a.

Kleipool, Q.: Recalculation of OPTEC5 Non-Linearity. Report containing the NL correction to be implemented in the data processor, Tech. rep. SRON-SCIA-PhE-RP-013, SRON, $2003 \mathrm{~b}$.

Kleipool, Q.: SCIAMACHY: Orbital Variation of dark signal, Tech. rep. SRON-SCIA-PhE-RP-18, SRON, 2004.

Kobayashi, H., Shimota, A., Kondo, K., Okumura, E., Kameda, Y., Shimoda, H., and Ogawa, T.: Development and evaluation of the Interferometric Monitor for Greenhouse Gases: a high throughput Fourier transform infrared radiometer for nadir Earth observations, Appl. Opt., 38, 6801-6807, 1999.

Platt, U.: Differential optical absorption spectroscopy (DOAS), in Air Monitoring by Spectroscopic Techniques, John Wiley, New York, 1994.

Reichle Jr., H. G., Anderson, B. E., Connors, V. S., Denkins, T. C., Forbes, D. A., Gormsen, B. B., Langenfels, R. L., Neil, D. O., Nolf, S. R., Novelli, P. C., Pougatchev, N. S., Roell, M. M., and Steele, L. P.: Space shuttle based global CO measurements during April and October 15 1994, MAPS instrument, data reduction, and data validation, J. Geophys. Res., 104, 21 443-21 454, 1999.

Rodgers, C.: Retrieval of atmospheric temperature and composition from remote measurements of thermal radiation, Rev. Geophys. Space Phys., 14, 609-624, 1976.

Schrijver, H.: Retrieval of carbon monoxide, methane and nitrous oxide from SCIAMACHY measurements, in: ESA WPP-161 1, vol. 5235, Proc. ESAMS, European Symposium on Atmospheric Measurements from Space, pp. 285-294, Estec, Nordwijk, The Netherlands, 2004.

Slijkhuis, S.: SCIAMACHY Level 0 to 1c Processing Algorithm Theoretical Baseline Document, ATBD: ENV-ATB-DLR-SCIA0041, DLR, 2001. 